\title{
The role of Livin expression in the clinicopathological features and prognosis of lung cancer: a meta-analysis
}

\author{
Min $\mathrm{Fei}^{1,2}$, Yingquan $\mathrm{Luo}^{2} \wedge$, Jian Zhou $^{3}$, Qian $\operatorname{Yan}^{1}$ \\ ${ }^{1}$ Department of Geriatrics, The Second Xiangya Hospital, Central South University, Changsha, China; ${ }^{2}$ Department of General Medicine, The \\ Second Xiangya Hospital, Central South University, Changsha, China; ${ }^{3}$ Department of Orthopedics, The Second Xiangya Hospital, Central South \\ University, Changsha, China \\ Contributions: (I) Conception and design: M Fei, Y Luo; (II) Administrative support: M Fei, Y Luo; (III) Provision of study materials or patients: \\ M Fei, Y Luo, Q Yan; (IV) Collection and assembly of data: M Fei, Y Luo, J Zhou; (V) Data analysis and interpretation: M Fei, Y Luo; (VI) \\ Manuscript writing: All authors; (VII) Final approval of manuscript: All authors. \\ Correspondence to: Yingquan Luo. Department of General Medicine, The Second Xiangya Hospital, Central South University, 139 Renmin Middle \\ Road, Changsha 410011, China. Email: luoyingquan@csu.edu.cn.
}

\begin{abstract}
Background: While the impact of Livin expression on patients with lung cancer was evaluated in previous studies, the results remained debatable. The relationship between Livin expression and clinicopathological features and prognosis in lung cancer was assessed in the present meta-analysis.

Methods: Web of Science, PubMed, Embase, Springer, Cochrane Library, China National Knowledge Internet database (CNKI), Wanfang database, Chinese VIP database and Chinese Biological Medical Database (CBM) were searched for relevant publications analyzing the role of Livin in prognosis and clinicopathological features of lung cancer before September 2020. The results were evaluated using pooled odds ratio (OR) and 95\% confidence intervals (CIs) calculated by STATA 12.0 software.

Results: Twenty studies with a total of 1,395 patients were enrolled in this meta-analysis based on inclusion and exclusion criteria. Livin expression was significantly associated with smoking status (OR $=2.51,95 \%$ CI: 1.70-3.72, $\mathrm{P}<0.05)$, lung adenocarcinomas (LAC) $(\mathrm{OR}=2.16,95 \% \mathrm{CI}: 1.60-2.92, \mathrm{P}<0.05)$, TNM stage (OR $=2.49,95 \%$ CI: $1.63-3.69, \mathrm{P}<0.05)$ and poor differentiation $(\mathrm{OR}=2.04,95 \% \mathrm{CI}: 1.35-3.08, \mathrm{P}<0.05)$. Livin expression was significantly related to metastasis ( $\mathrm{OR}=4.22,95 \% \mathrm{CI}$ : 2.68-6.64, $\mathrm{P}<0.05)$ and lower 5-year overall survival $(\mathrm{OR}=4.23,95 \% \mathrm{CI}: 2.60-6.88, \mathrm{P}<0.05)$ of patients with lung cancer.

Conclusions: The results of our study manifested that Livin expression was significantly related to smoking status, LAC, high TNM stage, poor differentiation, metastasis and 5-year overall survival rate, which indicated that Livin may be a potential biomarker for prognosis of lung cancer.
\end{abstract}

Keywords: Meta-analysis; Livin; lung cancer; overall survival; clinicopathological features

Submitted Sep 07, 2020. Accepted for publication Nov 20, 2020.

doi: $10.21037 /$ tcr-20-2835

View this article at: http://dx.doi.org/10.21037/tcr-20-2835

\section{Introduction}

As one of the most commonly diagnosed malignancies worldwide (1) that accounts for $33.3 \%$ of overall cancer mortality, lung cancer is the leading cause of cancer-related deaths (2). Despite recent advancements in treatment interventions, the prognosis of lung cancer patients has not been improved significantly (3). Therefore, it is important to understand the prognosis mechanism of lung cancer.

\footnotetext{
^ ORCID: 0000-0001-8930-8332.
} 
Livin is located on human chromosome 20q13.3 and contains a BIR domain and a RING finger domain. It is part of the group of inhibitory apoptotic proteins (IAP) and was discovered in 2000/2001. Like other IAP members, the $\mathrm{N}$-terminus of Livin comprises one or more tandem baculovirus IAP repeated sequence with anti-apoptotic effects (4). Specifically distributed in a variety of tumor tissues, Livin plays a role in the regulation of cell apoptosis through a variety of pathways. Apoptosis is known to be regulated by the following caspase-mediated pathways: the death receptor pathway, the mitochondrial pathway and the endoplasmic reticulum pathway (5). It has been reported that Livin is overexpressed in tumor tissues, and that the overexpression of Livin is closely related to tumor invasion, metastasis and treatment resistance $(6,7)$. In recent years, many studies focusing on the correlation between Livin expression and various tumors, such as melanoma (8), breast cancer (9), colorectal cancer (10), gastric cancer (11), hepatocellular carcinoma (12) and osteosarcoma (13) have shown that high Livin expression is a predictive biomarker of tumor progression and that Livin expression profile is useful for providing prognostic information. Consistently, Livin expression in lung cancer tissues has been found to be significantly higher than that in adjacent normal lung tissues and lung benign lesions (14-16). Although many studies have reported that Livin expression is associated with poor prognosis of lung cancer, the prognostic value of Livin expression in lung cancer patients remains controversial. For example, $\mathrm{Wu}$ and colleagues (15) have demonstrated that Livin expression is associated with tumor size, differentiation, TNM stage and metastasis. However, Zhang and colleagues (16) have verified that Livin expression is correlated with metastasis, but not with gender, age, smoking status, tumor size, differentiation and TNM stage. In this meta-analysis, all available literature was systematically evaluated to explore the prognostic value of Livin expression in patients with lung cancer. We present the following article in accordance with the PRISMA reporting checklist (available at http://dx.doi.org/10.21037/ tcr-20-2835).

\section{Methods}

\section{Search strategy and study selection}

All relevant published papers before September 2020 were retrieved with no language restrictions from Web of Science, PubMed, Embase, Springer, Cochrane Library,
China National Knowledge Internet database (CNKI), Wanfang database, Chinese VIP database and Chinese Biological Medical Database (CBM) by utilizing keywords "lung cancer, Livin and Inhibition apoptosis Protein (IAP)". Literature searching was conducted in detail by two investigators (Min Fei and Yingquan Luo).

\section{Inclusion and exclusion criteria}

Articles fulfilling the following criteria were included in our analysis:

(I) Patients being studied had lung cancer confirmed by pathological diagnosis;

(II) Contained sufficient prognostic and clinicopathological parameters for analysis, including age, gender, tumor size, smoking status, pathological classification, TNM stage, differentiation, metastasis or overall survival;

(III) Patients being studied had no preoperative treatments.

Articles with the following conditions were excluded:

(I) Not published as an original article or review, such as cell and animal experiments, case reports, communications, expert opinions, letters and editorials;

(II) Contained no cut-off value;

(III) Similar studies by the same author;

(IV) Studies based on blood specimens;

(V) Patients being studied had lung cancer not diagnosed by a biopsy.

\section{Data extraction}

The eligibility of all retrieved documents was assessed and relevant information was independently recorded the relevant information by Min Fei and Qian Yan. To eliminate discrepancy, the extracted data, which included authors, publication year, Livin detection method, cut-off definition, age, sex, TNM stage, differentiation, metastasis, smoking status and 5-year overall survival, were checked by Jian Zhou. The corresponding authors were consulted for further information when required.

\section{Quality evaluation}

The quality of the included literature was assessed using Newcastle-Ottawa Scale (NOS) (17). All included studies had a quality assessment score of $\geq 7$ stars. Quality 


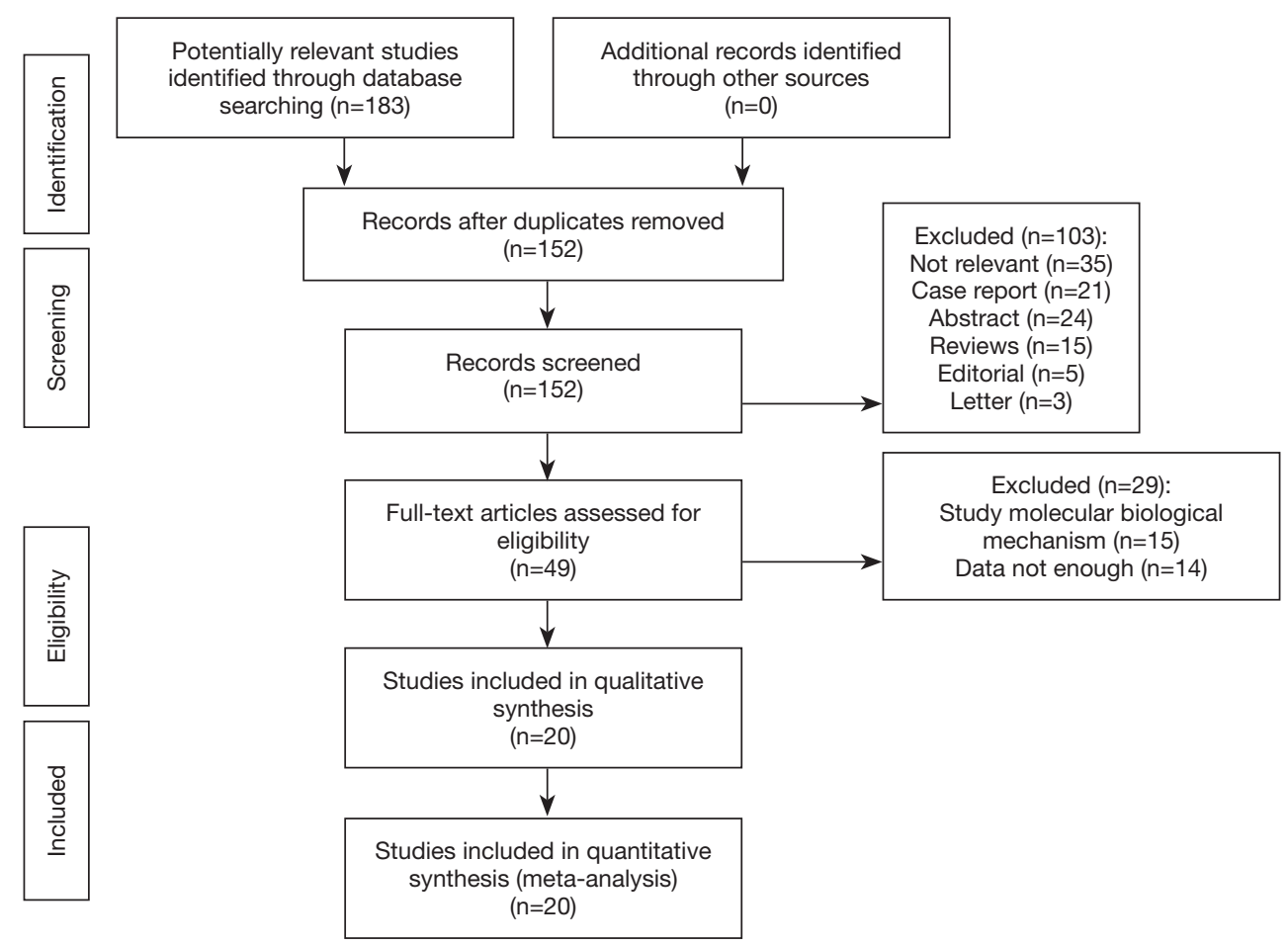

Figure 1 The flow diagram of literature screening. From: Moher D, Liberati A, Tetzlaff J, et al. Preferred Reporting Items for Systematic Reviews and Meta-Analyses: The PRISMA Statement. PLoS Med 2009;6:e1000097.

evaluation was independently conducted by Min Fei and Qian Yan. Discrepancies were resolved through discussion.

\section{Statistical analyses}

Statistical analyses were performed using STATA 12.0 software (Stata Corp LP, College Station, TX, USA) with $\mathrm{P}<0.05$ considered to be statistically significant. Heterogeneity evaluation of included studies was conducted. In the absence of significant heterogeneity, the fixed-effect model (FEM) was selected for analysis (18). Otherwise, the random-effects model (REM) was used to lower the effect of heterogeneity (19). To analyze the prognostic value of Livin on lung cancer, OR with corresponding 95\% confidence interval $(95 \%$ CI) was calculated. The results presented in the form of forest plots were considered to be relevant when the overall $95 \%$ CI horizontal line of all enrolled studies did not intersect the invalid vertical line, but fell on the right side of the invalid line instead.

In addition, the stability of conclusion was appraised using sensitivity analysis through sequential removal of individual studies. To identify publication bias, Egger and Begg funnel plots were used. Symmetrical funnel plots or $\mathrm{P}>0.05$ (Egger test) suggest the absence of publication bias, while asymmetric funnel plots or $\mathrm{P}<0.05$ (Egger test) indicate the presence of publication bias (20).

\section{Results}

\section{Basic information of studies}

A total of 183 articles were initially retrieved from various databases. There were still 151 articles after the removal of duplicating studies, following which 49 studies remained after the elimination of comments, case reports, metaanalyses and unrelated studies. Next, with further review, 15 studies that were limited to molecular biological mechanism investigation, and another 14 studies that did not offer sufficient data (OR and 95\% CI) were excluded. Finally, 20 studies (14-16,21-37) with a total of 1,395 patients were incorporated in this meta-analysis (Figure 1). The basic information of studies was shown in Table 1 and Table 2. Number of included patients in each study ranged from 30 to 216 (median 123). The expression of Livin was detected using immunohistochemistry (IHC) in 19 studies, and western blot (WB) in 1 study. Most of these eligible articles selected Asian populations as the research object. 
Table 1 The basic characteristics of the included literature.

\begin{tabular}{|c|c|c|c|c|c|c|c|c|c|c|}
\hline Ref & Study & Year & Cases & $\begin{array}{l}\text { Livin expression } \\
(\mathrm{P} / \mathrm{N})\end{array}$ & Age (median) & Method & NOS & Inclusion period & $\begin{array}{l}\text { Preoperative } \\
\text { treatment }\end{array}$ & Livin cut-off \\
\hline (14) & Chai et al. & 2019 & 108 & $56 / 52$ & NR & SP & 8 & 2011-2017 & No & $\mathrm{A} 1^{\star} \mathrm{B}>3$ \\
\hline$(21)$ & Liang et al. & 2017 & 90 & $52 / 38$ & NR & $\mathrm{IHC}$ & 8 & 2004-2009 & No & $(\mathrm{A} 3+\mathrm{B}) / 2 \geq 4$ \\
\hline (16) & Zhang et al. & 2016 & 45 & $31 / 14$ & 58.5 & SP & 7 & 2013-2014 & No & $A 3^{\star} B>1$ \\
\hline (24) & Su et al. & 2016 & 216 & $137 / 79$ & 60 & SP & 8 & 2007-2014 & No & $A 5^{\star} \mathrm{B}>3$ \\
\hline$(25)$ & Wang et al. & 2014 & 88 & $51 / 37$ & NR & $\mathrm{IHC}$ & 7 & 2007-2008 & No & $A 3^{\star} B \geq 3$ \\
\hline (29) & Han et al. & 2012 & 40 & $26 / 14$ & 62 & $\mathrm{IHC}$ & 7 & 2006-2008 & No & $A 3^{*} B \geq 2$ \\
\hline (30) & Yang et al. & 2012 & 52 & $24 / 28$ & NR & SP & 7 & 2004-2006 & No & $\mathrm{A} 1^{\star} \mathrm{B}>3$ \\
\hline (31) & Zhang et al. & 2012 & 50 & $44 / 6$ & 62 & $\mathrm{IHC}$ & 7 & 2001-2005 & No & $A 3^{\star} B \geq 1$ \\
\hline (32) & Zhuang et al. & 2012 & 46 & $31 / 15$ & 59 & $\mathrm{IHC}$ & 8 & 2010-2011 & No & $A 3 \geq 1$ \\
\hline (33) & Yan et al. & 2011 & 40 & $28 / 12$ & NR & $\mathrm{IHC}$ & 7 & 2009-2011 & No & $A 1 \geq 2$ \\
\hline (34) & Li et al. & 2010 & 43 & $29 / 14$ & 56.3 & SP & 7 & 2007-2009 & No & $\mathrm{A} 1 \geq 2$ \\
\hline (35) & Sun et al. & 2008 & 30 & $17 / 13$ & 54.5 & SP & 7 & 2003-2006 & No & $A 3+B \geq 1$ \\
\hline
\end{tabular}

A, positive cell percentage; A1, scored 1 ( $\leq 10 \%), 2$ (10-50\%), 3 (50-75\%), 4 (>75\%); A2 scored 1 ( $\leq 25 \%), 2(26-50 \%), 3(51-75 \%), 4$ (>75\%); A3, scored 1 ( $\leq 5 \%), 2$ (6-25\%), 3 (25-50\%), 4 (>51\%); A4, scored 1 ( $\leq 70 \%), 2$ (71-80\%), 3 (81-90\%), 4 (>90\%); A5, scored 1 ( $\leq 10 \%), 2(10-30 \%), 3$ (30-70\%), 4 (>70\%); B, staining intensity; scored 0 (absence of staining), 1 (weak staining), 2 (moderate staining), 3 (strong staining); C, Gray value of Livin protein expression divided by gray value of GAPDH in Western blot $>0.01$. IHC, immunohistochemistry; SP, streptavidin peroxidase; SABC, streptavidin-biotin complex; WB, Western Blot; NR, no report; P, positive; N, negative.

The NOS scores of included studies were $\geq 7$ (with a mean value of 7.25).

\section{Correlation between Livin expression and clinicopathological features}

As indicated in Figure 2, there was no significant heterogeneity detected all included studies $\left(\mathrm{I}^{2} \leq 50 \%\right)$. Consequently, fixed effect model was used to assess the association between Livin expression and lung cancer clinicopathological features. Our meta-analysis revealed that Livin expression was found to be unrelated to age (OR
$=0.99,95 \%$ CI: 0.73-1.34, P> 0.05; Figure 2A), gender $(\mathrm{OR}$ $=0.97,95 \%$ CI: $0.64-1.47, \mathrm{P}>0.05$; Figure $2 B$ ) and tumor size $(\mathrm{OR}=0.94,95 \% \mathrm{CI}: 0.50-1.78, \mathrm{P}>0.05$; Figure $2 C)$. Conversely, Livin expression was found to be significantly associated statistically with smoking status ( $\mathrm{OR}=2.51,95 \%$ CI: $1.70-3.72, \mathrm{P}<0.05$; Figure $2 D)$, LAC $(\mathrm{OR}=2.16,95 \%$ CI: $1.60-2.92, \mathrm{P}<0.05$; Figure $2 E$ ), high TNM stage (OR $=2.49,95 \%$ CI: $1.69-3.69, \mathrm{P}<0.05$; Figure $2 F)$ and poor differentiation $(\mathrm{OR}=2.04,95 \% \mathrm{CI}: 1.35-3.08, \mathrm{P}<0.05$; Figure $2 G$ ). In particular, Livin expression was revealed to be significantly correlated with metastasis $(\mathrm{OR}=4.22,95 \% \mathrm{CI}$ : 2.68-6.64, $\mathrm{P}<0.05$; Figure $2 \mathrm{H}$ ) and reduced 5 -year overall 


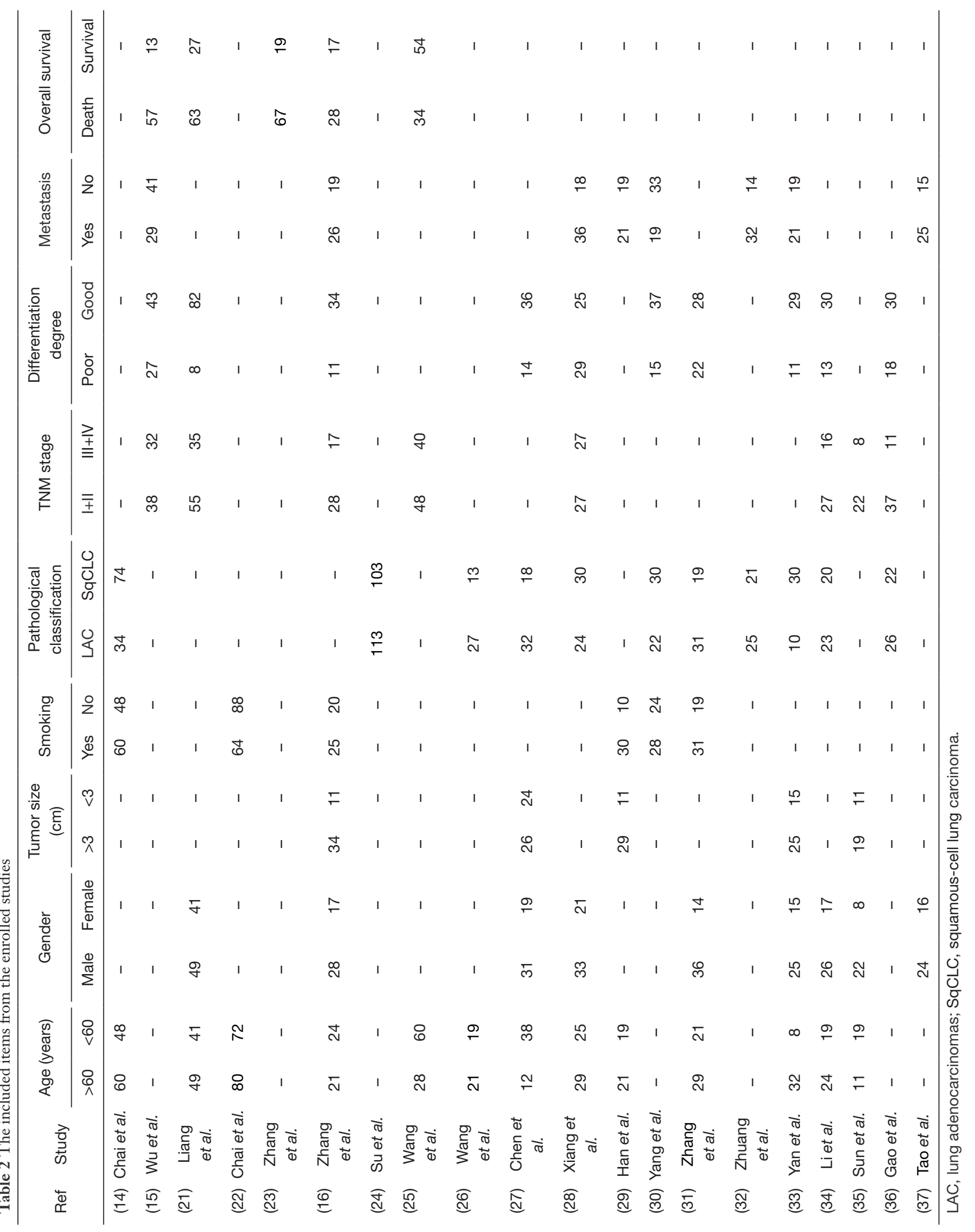




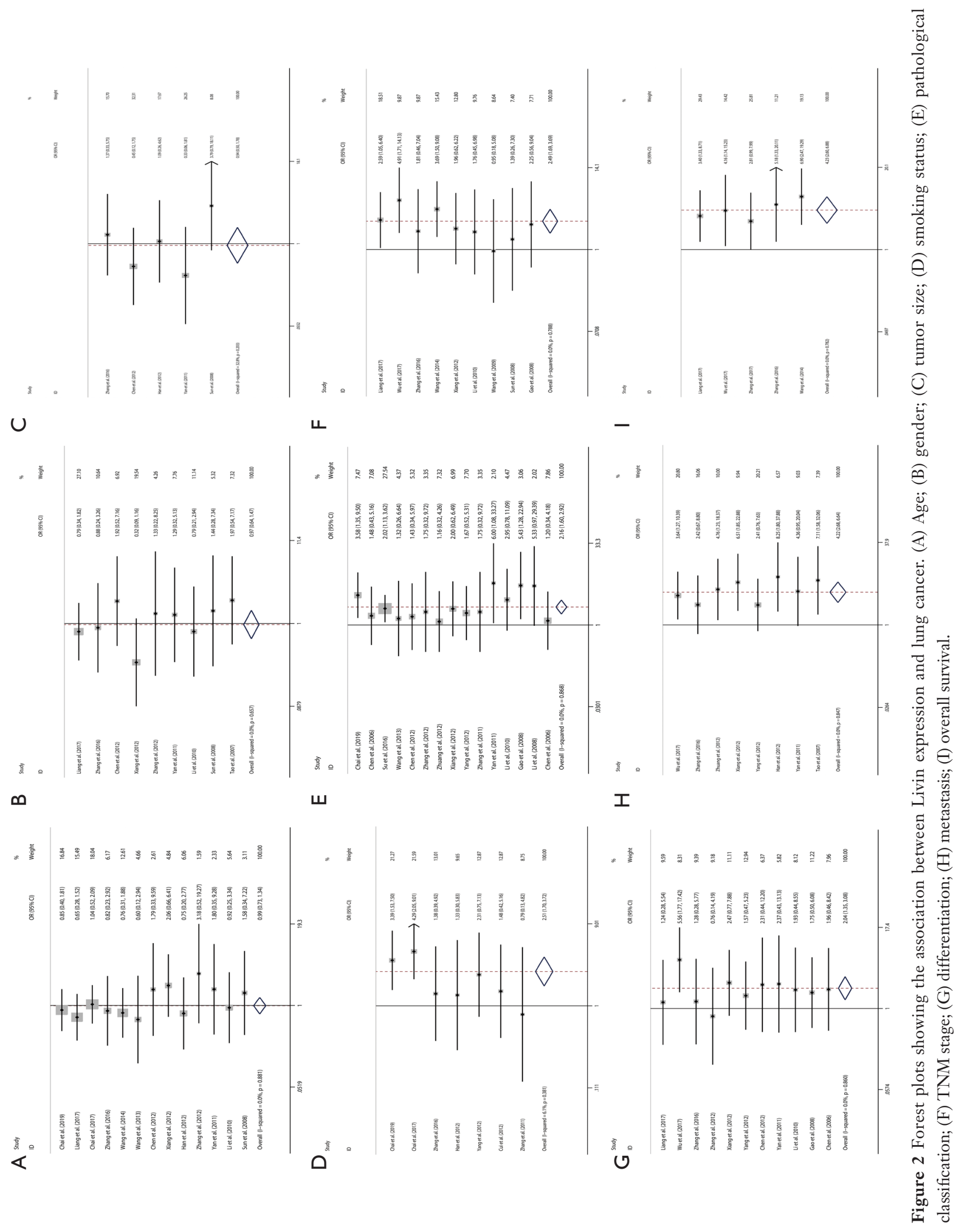


A

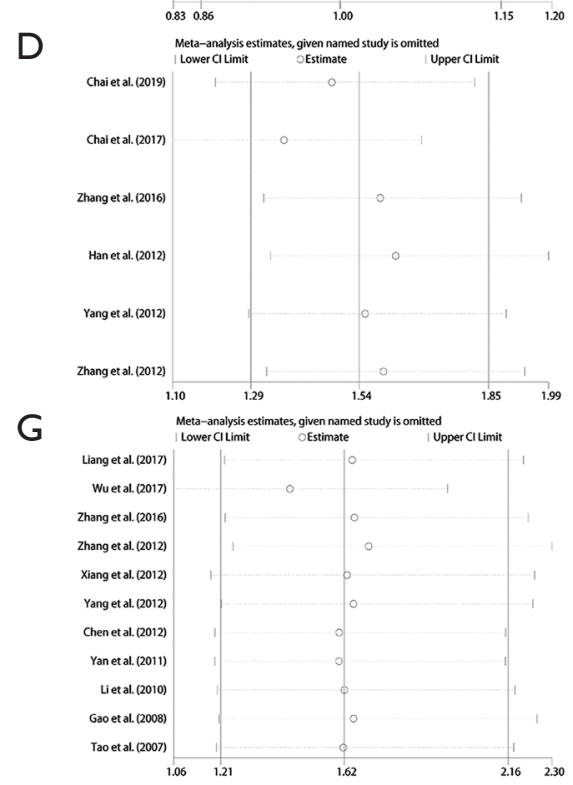

B

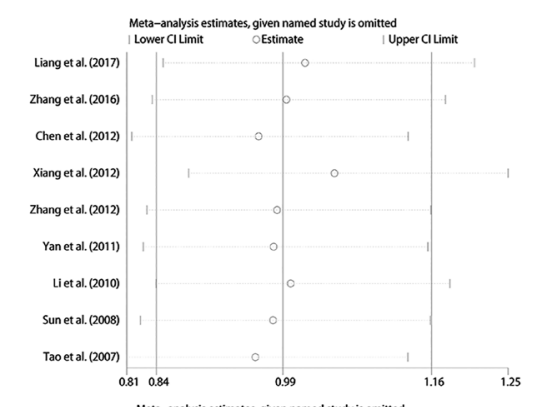

E

$\mathrm{H}$
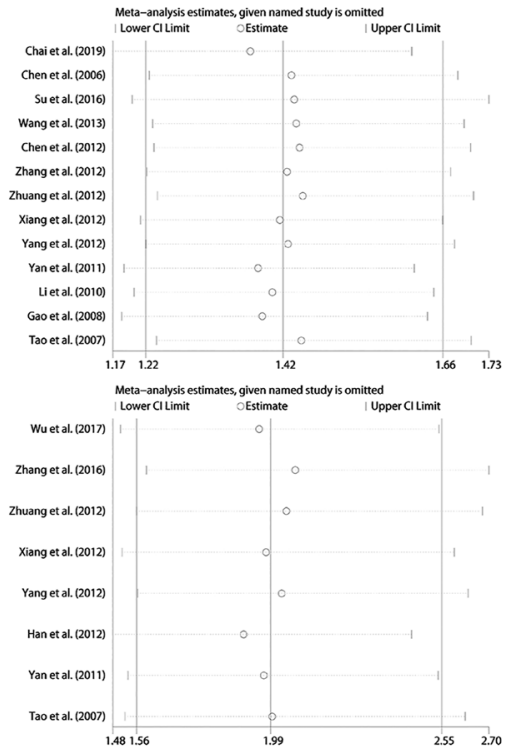

C

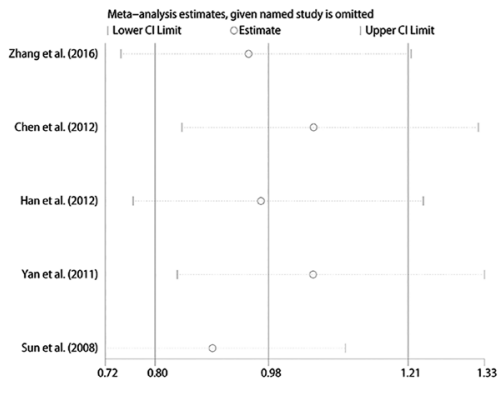

$\mathrm{F}$
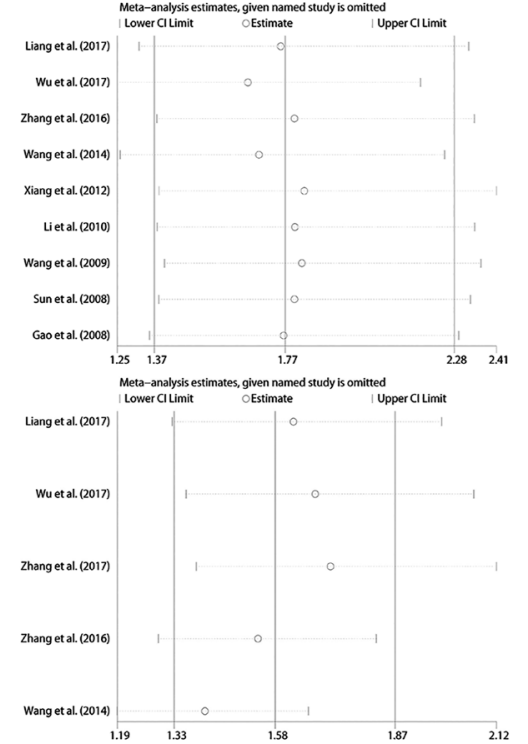

Figure 3 Sensitivity analysis on the association of Livin expression in lung cancer patients. (A) Age; (B) gender; (C) tumor size; (D) smoking status; (E) pathological classification; (F) TNM stage; (G) differentiation; (H) metastasis; (I) overall survival.

survival ( $\mathrm{OR}=4.23,95 \%$ CI: 2.60-6.88, $\mathrm{P}<0.05$; Figure $2 I)$. The combined OR suggested that Livin expression was significantly associated with metastasis and overall survival in lung cancer patients.

\section{Sensitivity analyses}

The stability of our results was estimated by sensitivity analysis by excluding one study after another. Our analysis showed that there were no significant changes in OR and heterogeneity, and that our findings were not impacted by any study, which was an indication of the credibility of our conclusion (Figure 3).

\section{Publication bias}

As shown in Figure 4, substantially symmetrical funnel plots (A,B,C,E,F,G,H,I) indicated the absence of significant publication bias $(\mathrm{P}>0.05)$ in the association between Livin expression and age, gender, tumor size, pathological classification, TNM stage, differentiation, metastasis and overall survival. However, asymmetrical funnel plot (D) indicated the presence of publication bias $(\mathrm{P}<0.05)$ in the association between Livin positive expression and smoking status. In order to make sure that all included articles conformed to the inclusion criteria and were eligible, the association between smoking status and lung cancer outlined in the included studies was carefully reviewed. Studies with desired results that were published more easily may contribute to publication bias, so the conclusion from these studies should be treated with caution.

\section{Discussion}

Lung cancer is a disease with poor prognosis characterized by the highest rates of mortality and morbidity among 

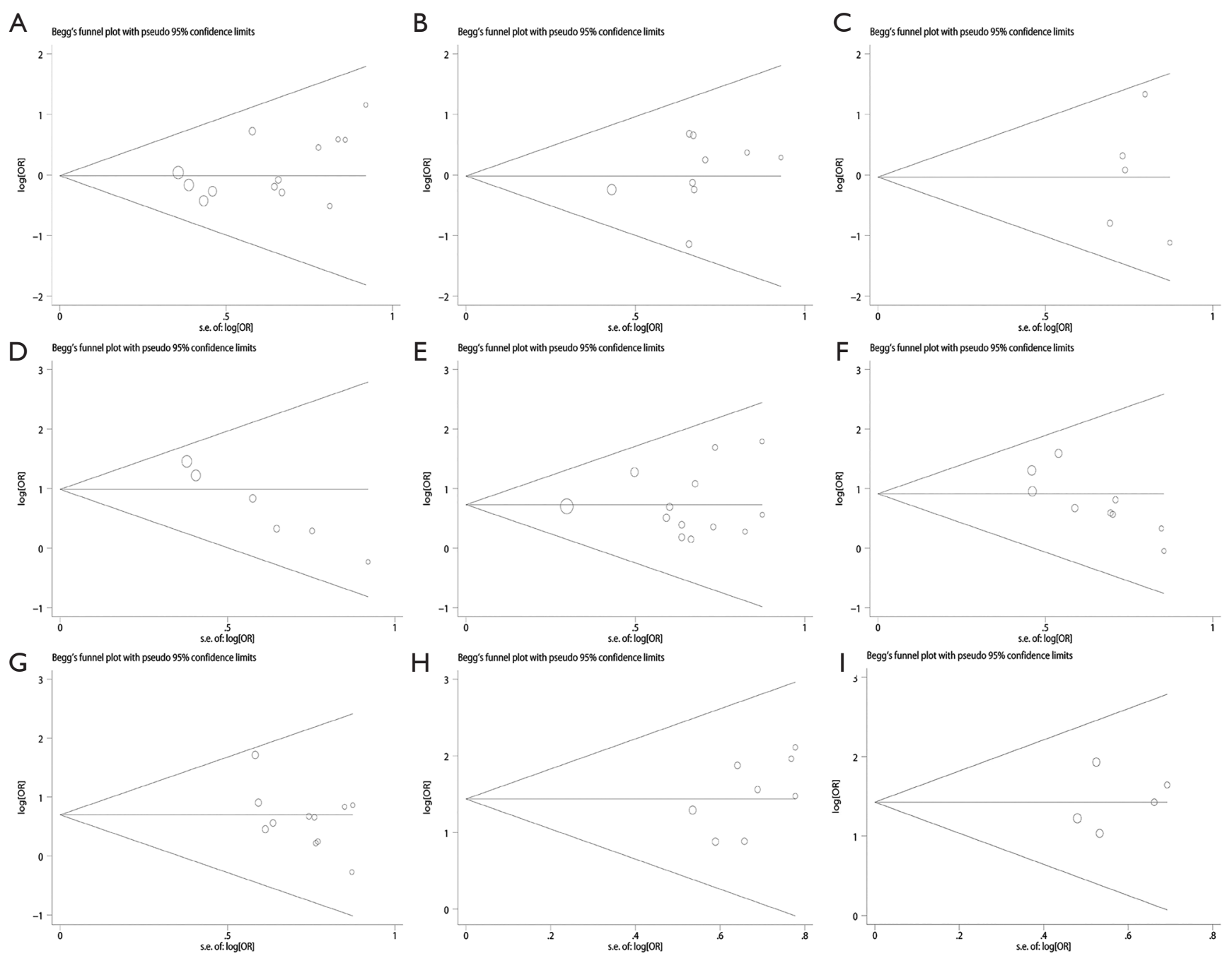

Figure 4 Funnel plots assessing possible publication bias for the relation between Livin and lung cancer. (A) Age; (B) gender; (C) tumor size; (D) smoking status; (E) pathological classification; (F) TNM stage; (G) differentiation; (H) metastasis; (I) overall survival.

other cancer types $(38,39)$, and represents a significant clinical challenge. The efficacy of traditional lung cancer treatment interventions, including surgery, radiotherapy and chemotherapy has been unsatisfactory (40). Accordingly, in order to improve the life quality of patients, effective treatment strategies that can decrease tumor recurrence and treatment resistance have gained much research attention in recent years, especially targeted therapy and immunotherapy $(41,42)$. Nevertheless, the mortality rate has not been improved significantly (43). Hence, the discovery of novel prognostic biomarkers and targets is urgently in need to improve treatment efficacy.

Similar to other solid tumors, lung cancer is resistant to apoptosis (44). Therefore, targeting of apoptotic pathway represents a promising method in the identification of normal cells and in the selective killing of cancer cells. Highly expressed IAP in malignant tumors has been shown to tightly control the level of cell apoptosis (45). As a member of the IAP family, Livin inhibits tumor cells from undergoing apoptosis, leading to infinite cell proliferation and metastasis (46). Livin plays an apoptotic role by binding with caspases (5) or by activating the TAK1/JNK1 pathway (47). Previous studies have found that Livin is overexpressed in lung cancer, and that overexpression of Livin is strongly associated with lung cancer prognosis and diagnosis. This meta-analysis systematically evaluated the 
effect of Livin on the prognostic outcome of lung cancer patients.

Here, we demonstrated significant association between Livin expression and smoking status $(\mathrm{OR}=2.51,95 \% \mathrm{CI}$ : 1.70-3.72, $\mathrm{P}<0.05)$, LAC $(\mathrm{OR}=2.16,95 \% \mathrm{CI}: 1.60-2.92$, $\mathrm{P}<0.05)$, high TNM stage $(\mathrm{OR}=2.49,95 \%$ CI: $1.69-3.69$, $\mathrm{P}<0.05)$, and poor differentiation ( $\mathrm{OR}=2.04$, 95\% CI: $1.35-$ 3.08, $\mathrm{P}<0.05)$. Furthermore, Livin expression was found to be associated with tumor metastasis $(\mathrm{OR}=4.22,95 \% \mathrm{CI}$ : 2.68-6.64, $\mathrm{P}<0.05)$, and 5-year survival rate $(\mathrm{OR}=4.23,95 \%$ CI: 2.60-6.88, $\mathrm{P}<0.05)$. However, Livin was shown to be unrelated to age, gender and tumor size. In our assessment of outcome stability by sensitivity analyses, when a single study was removed, there were no significant changes of pooled OR, indicating that the results were consolidated. Significant association between Livin expression and lung cancer prognosis may be attributed to the binding between the BIR domain of Livin and caspase-3, 7 and 9, a process which inhibits caspase activity and blocks the apoptosis signal transduction of tumor cells (48). Alternatively, Livin may bind TAB1 to mediate the activation of JNK1 through TAB1 activation, a process which inhibits cell apoptosis (49) and subsequently causes tumor cell to metastasis and invasiveness. Clearly, Livin is a promising biomarker of lung cancer clinicopathologic features.

This study has a number of limitations. Firstly, the cut-off values for Livin expression were based on positive cell percentage and staining intensity. The cut-off values were not exactly the same, which may contribute to study bias. According to previous studies, although different cut-off values may not affect the final conclusion $(50,51)$, the conclusion should be treated with caution. Secondly, studies with desired results were more easily released, and publication bias was found for the association between Livin expression and smoking status. Thirdly, most subjects in all eligible literature were from Asia. Therefore, a detailed study with larger sample size is essential to comprehensively appraise the prognostic value of Livin in lung cancer.

\section{Conclusions}

Taken together, for the first time, we discuss the association between Livin expression and lung cancer. Our metaanalysis suggests that Livin expression is significantly associated with smoking status and LAC $(\mathrm{P}<0.05)$, indicating that Livin may be a potential diagnostic biomarker of LAC.

Moreover, our results show that Livin expression is associated with high TNM stage, poor differentiation, metastasis and low 5-year overall survival of lung cancer $(\mathrm{P}<0.05)$, suggesting that Livin may be a candidate prognostic biomarker for lung cancer. Due to the limitations, more rigorous and well-designed investigations are necessary to better estimate the prognostic role of Livin in lung cancer.

\section{Acknowledgments}

Funding: None.

\section{Footnote}

Reporting Checklist: The authors have completed the PRISMA reporting checklist. Available at http://dx.doi. org/10.21037/tcr-20-2835

Conflicts of Interest: All authors have completed the ICMJE uniform disclosure form (available at http://dx.doi. org/10.21037/tcr-20-2835). The authors have no conflicts of interest to declare.

Ethical Statement: The authors are accountable for all aspects of the work in ensuring that questions related to the accuracy or integrity of any part of the work are appropriately investigated and resolved.

Open Access Statement: This is an Open Access article distributed in accordance with the Creative Commons Attribution-NonCommercial-NoDerivs 4.0 International License (CC BY-NC-ND 4.0), which permits the noncommercial replication and distribution of the article with the strict proviso that no changes or edits are made and the original work is properly cited (including links to both the formal publication through the relevant DOI and the license). See: https://creativecommons.org/licenses/by-nc-nd/4.0/.

\section{References}

1. Zhou JS, Yang ZS, Cheng SY, et al. miRNA-425-5p enhances lung cancer growth via the PTEN/PI3K/AKT signaling axis. BMC Pulm Med 2020;20:223.

2. Global Burden of Disease Cancer Collaboration, Fitzmaurice C, Akinyemiju TF, et al. Global, Regional, and National Cancer Incidence, Mortality, Years of Life Lost, Years Lived With Disability, and Disability-Adjusted LifeYears for 29 Cancer Groups, 1990 to 2016: A Systematic Analysis for the Global Burden of Disease Study. JAMA 
Oncol 2018;4:1553-68.

3. Hao Q, Tang H. Interferon-gamma and Smac mimetics synergize to induce apoptosis of lung cancer cells in a TNFalpha-independent manner. Cancer Cell Int 2018;18:84.

4. Zhao X, Yuan Y, Zhang ZQ, et al. Effects of shRNAsilenced Livin and survivin on lung cancer cell proliferation and apoptosis. JBUON 2014;19:757-62.

5. Kasof GM, Gomes BC. Livin, a novel inhibitor of apoptosis protein family member. J Biol Chem 2001;276:3238-46.

6. Zhang Z, Dou X, Yang H, et al. Association of expression of p53, Livin, ERCC1, BRCA1 and PARP1 in epithelial ovarian cancer tissue with drug resistance and prognosis. Pathol Res Pract 2020;216:152794.

7. Altieri B, Sbiera S, Casa SD, et al. Livin/BIRC7 expression as malignancy marker in adrenocortical tumors. Oncotarget 2017;8:9323-38.

8. Zhou J, Li J, Guleria I, et al. Immunity to X-linked inhibitor of apoptosis protein (XIAP) in malignant melanoma and check-point blockade. Cancer Immunol Immunother 2019;68:1331-40.

9. Han Y, Zhang L, Wang W, et al. Livin promotes the progression and metastasis of breast cancer through the regulation of epithelialmesenchymal transition via the $\mathrm{p} 38$ / GSK3beta pathway. Oncol Rep 2017;38:3574-82.

10. Badr EA, Assar MF, Eltorgoman AMA, et al. A correlation between BCL-2 modifying factor, p53 and Livin gene expressions in cancer colon patients. Biochem Biophys Rep 2020;22:100747.

11. Chung CY, Park YL, Kim N, et al. Expression and prognostic significance of Livin in gastric cancer. Oncol Rep 2013;30:2520-8.

12. Guo H, Gao YT, Zhang Q, et al. Expression and clinical significance of Livin protein in hepatocellular carcinoma. Dis Markers 2013;35:489-96.

13. Sun K, Liao Q, Chen Z, et al. Expression of Livin and PlGF in human osteosarcoma is associated with tumor progression and clinical outcome. Oncol Lett 2018;16:4953-60.

14. Chai CY, Liu YP, Wang T, et al. Expression and clinical significance of Livin protein and STAT3 protein in bronchogenic carcinoma. Modern Oncology 2019;27:420-4.

15. Wu YG, Sun XF. The clinical significance of HIF-1 and Livin protein expression in lung adenocarcinoma and squamous cell carcinoma. Journal of Jiangsu University (Medicine Edition) 2017;27:445-8.
16. Zhang CY, Yang Y, Liu DL, et al. The expression and significance of Livin and Survivin proteins in nonsmall cell lung cancer. Chinese Journal of Gerontology 2016;36:794-6.

17. Ofek Shlomai N, Rao S, Patole S. Efficacy of interventions to improve hand hygiene compliance in neonatal units: a systematic review and meta-analysis. Eur J Clin Microbiol Infect Dis 2015;34:887-97.

18. Mantel N, Haenszel W. Expression and clinical significance of Livin protein in hepatocellular carcinoma. J Natl Cancer Inst 1959;22:719-48.

19. DerSimonian R, Laird N. Meta-Analysis in Clinical Trials. Control Clin Trials 1986;7:177-88.

20. Egger M, Smith GD, Schneider M, et al. Bias in metaanalysis detected by a simple, graphical test. BMJ 1997;315:629-34.

21. Liang Y, Wang H, Sun Y, et al. miR-198-induced upregulation of Livin may be associated with the prognosis and contribute to the oncogenesis of lung adenocarcinoma. Oncol Rep 2017;38:2096-104.

22. Chai CY, Huo SF, Jiao WW, et al. The expression and clinical significance of Livin and PTEN in bronchial lung cancer. Shanxi Medical Journal 2017;46:1314-7.

23. Zhang F, Yan CL. The relationships between expression of PD-L1 and apoptosis-related protein in lung adenocarcinoma. Modern Oncology 2017;25:3256-60.

24. Su WM, Wang Y, Ye HY, et al. Expression of Livin in lung cancer and its correlation with Fas/FasL. Pharmaceutical Research Journal 2016;35:610-3.

25. Wang YL, Wang D, Guo H, et al. Expression of Livin in Non-small Cell Lung Cancer and its Clinical Significance. Progress in Modern Biomedicine 2014;14:748-51.

26. Wang D, Qian YH, Wang GS, et al. The Nuclear Staining of Survivin and Livin and Its Clinical Significance in NonSmall Cell Lung Cancer. J Trop Med 2013;13:155-7.

27. Chen YS, Wang GQ, Li HR, et al. Expression of Livin and CXCR4 Protein in Lung Cancer Tissue and Their Relationship with Clinicopathological Features. China Cancer 2012;22:748-52.

28. Xiang J, Lu YJ. Expression of Ki-67 and Livin proteins in human non-small cell lung cancer. Anhui Medical Journal 2012;33:405-8.

29. Han BL, Li LF, Wu Y. Expression of Bax, Livin and Survivin in non-small cell lung cancer tissues. Tianjin Med J 2012;40:513-5.

30. Yang X, Zang J, Chai CY, et al. Expression of Livin in primary lung cancer and its clinical significance. Chin J Clinicians (Electronic Edition) 2012;6:2366-9. 
31. Zhang JR, Li T, Chen S. Expression and significance of Survivin and Livin in non-small cell lung cancer. Clinical Pulmonary Medicine Journal 2012;17:101-3.

32. Zhuang L, Duan LC, Yang RX, et al. The clinical significance of extraordinary positive expression of Livin IAP in NSCLC. Modern Preventive Medicine 2012;39:747-9.

33. Yan HE, Jiang WY, Bao WH, et al. The expression and significance of Livin and NF- $\mathrm{B}$-p65 in non-small cell lung cancer. Heilong Jiang Medicine and Pharmacy 2011;34:15-7.

34. Li L, Cao BJ, Wang LN, et al. The expression and clinical significance of Livin gene in non-small cell lung cancer. Modern Oncology 2010;18:2366-7.

35. Sun B, Wang JG, Huang L, et al. Expression of Livin in Small Cell lung Cancer and its correlation with Caspase-3. Medicine and Philosophy (Clinical Decision Making Forum Edition) 2008;29:19-21.

36. Gao Y, Xia QA, Wu Y, et al. Expression and significance of Livin in non-small cell lung Carcinoma. Shan Dong Medicine 2008;48:17-9.

37. Tao XN, Zhang XJ, Chen M. Expression and pathological significance of Livin and P53 in non-small cell lung cancer. Chinese Journal of Histochemistry and Cytochemistry 2007;16:293-6.

38. Wang C, Wu Y, Shao J, et al. Clinicopathological variables influencing overall survival, recurrence and postrecurrence survival in resected stage I non-small-cell lung cancer. BMC Cancer 2020;20:150.

39. Bray F, Ferlay J, Soerjomataram I, et al. Global cancer statistics 2018: GLOBOCAN estimates of incidence and mortality worldwide for 36 cancers in 185 countries. CA Cancer J Clin 2018;68:394-424.

40. Fehrenbacher L, von Pawel J, Park K, et al. Updated Efficacy Analysis Including Secondary Population Results for OAK: A Randomized Phase III Study of Atezolizumab versus Docetaxel in Patients with Previously Treated

Cite this article as: Fei M, Luo Y, Zhou J, Yan Q. The role of Livin expression in the clinicopathological features and prognosis of lung cancer: a meta-analysis. Transl Cancer Res 2021;10(1):99-109. doi: 10.21037/tcr-20-2835
Advanced Non-Small Cell Lung Cancer. J Thorac Oncol 2018;13:1156-70.

41. Siegel RL, Miller KD, Jemal A. Cancer statistics, 2020. CA Cancer J Clin 2020;70:7-30.

42. Díaz-García CV, Agudo-Lopez A, Perez C, et al. DICER1, DROSHA and miRNAs in patients with non-small cell lung cancer: implications for outcomes and histologic classification. Carcinogenesis 2013;34:1031-8.

43. Takenaka T, Takenoyama M, Inamasu E, et al. Role of surgical resection for patients with limited disease-small cell lung cancer. Lung Cancer 2015;88:52-6.

44. Wallach D, Kang TB, Dillon CP, et al. Programmed necrosis in inflammation: Toward identification of the effector molecules. Science 2016;352:aaf2154.

45. Yoon TM, Kim SA, Lee DH, et al. Livin enhances chemoresistance in head and neck squamous cell carcinoma. Oncol Rep 2017;37:3667-73.

46. Du $M$, Wang Y, Zhao W, et al. Study on the relationship between Livin expression and osteosarcoma. J Bone Oncol 2018;12:27-32.

47. Sanna MG, da Silva Correia J, Ducrey O, et al. IAP suppression of apoptosis involves distinct mechanisms: the TAK1/JNK1 signaling cascade and caspase inhibition. Mol Cell Biol 2002;22:1754-66.

48. Liu F, Chang H, Xu W, et al. The effects of Livin shRNA on the response to cisplatin in HepG2 cells. Oncol Lett 2015;10:2957-61.

49. Lin X, Li HR, Lin XF, et al. Silencing of Livin inhibits tumorigenesis and metastasis via VEGF and MMPs pathway in lung cancer. Int J Oncol 2015;47:657-67.

50. Wu YY, Zang Z, Wang J, et al. Meta analysis of the expression and clinical relevance of Livin in gastric cancer. China Medical Herald 2017;14:73-9.

51. Huang SQ. A meta-analysis of the correlation between Livin and oral squamous cell carcinoma. Clinical Medicine 2017;14:73-9. 